\title{
Influencing Effect of Heat Therapy on Osteoblasts Growth and Differentiation Following Treatment with Bone Antiresorptive Drugs- An in vitro Study
}

\author{
Alqhtani NR ${ }^{1, *}$, Adel Alenazi ${ }^{1}$, Fazil Arshad Nasyam ${ }^{1}$, Sajeda Mehaji ${ }^{2}$ \\ 'Department of Oral and Maxillofacial Surgery and Diagnostics Sciences, College of Dentistry, Prince Sattam Bin Abdul Aziz University, Alkarj, SAUDI ARABIA. \\ 2Department of Emeritus Reader in Oral Biology, Eastman Dental Institute University College-London, London, UNITED KINGDOM.
}

\begin{abstract}
Objectives: To find out the effect of mild heat shock on osteoblast proliferation and mineralisation following treatment with bisphosphonates. Materials and Methods: Cell culture of MC3T3 cells was performed in alpha minimum essential medium supplemented with $10 \%$ Foetal Calf Serum (FCS), $2 \mathrm{mmol}$ L-glutamine and $100 \mathrm{U} / \mathrm{ml}$ each of penicillin/streptomycin and were incubated at $37^{\circ} \mathrm{C}$ in humidified $5 \% \mathrm{CO}_{2}$. The selected bisphosphonate drugs were administered, following which heat therapy was given by placing the flasks in a temperature-regulated water bath. The proliferation of osteoblast progenitors was measured using the methylene blue staining technique. Results: The results showed that mild heat-shock for $2 \mathrm{~min}$ at $42^{\circ} \mathrm{C}$ can stimulate proliferation of osteoblast progenitors, as well as bone nodule formation. In addition, mild heat-shock can reverse
\end{abstract}

the action of bisphosphonate by stimulation of osteoblast proliferation and mineralisation. Conclusion: Mild heat-shock enhances cell differentiation and osteoblasts mineralisation following bisphosphonate treatment. Key words: Bisphosphonates, Heat-shock, Osteoblast, Osteoclast.

Correspondence

Dr. Alqhtani NR,

Department of Oral and Maxillofacial Surgery and Diagnostics Sciences, College of Dentistry, Prince Sattam Bin Abdul Aziz University, Alkarj, SAUDI ARABIA.

Email: drnasserpsau@gmail.com

DOI: 10.5530/jyp.2019.11.81

\section{INTRODUCTION}

Bone along with the cartilage constitutes the body's skeleton. ${ }^{1}$ Bone remodelling is the process by which bone is turned over and it maintains the integrity of the skeleton. ${ }^{2}$ Initially there will be activation of osteoclasts by osteoblasts, the osteoblasts get recruited to the desorption site and then they proliferate and differentiate, resulting in new bone formation. ${ }^{3}$ The whole process is regulated by local and systemic hormonal factors. Any disturbance in this process leads to pathological conditions like periodontal disease, osteoporosis or osteonecrosis etc. ${ }^{2,3}$

The aetiology of Osteonecrosis of the Jaw (ONJ) is infection, trauma, medication and radiotherapy. ${ }^{4}$ ONJ is primarily associated with radiation therapy, as a correlation between bisphosphonate and ONJ was reported. ${ }^{4,5}$ Bisphosphonates are given to patients with osteoporosis, malignant bone disease and hypercalcaemia of malignancy and one of its complication is bisphosphonate induced osteonecrosis of the jaws (BRONJ) or chemo-osteonecrosis of the jaw, caused by binding of the drug to the bone matrix. ${ }^{6}$ In adults with cancer-related bone metastases, use of zoledronic acid, a bisphosonate caused ONJ in $1.3 \%$ of patients. Bisphosphonates inactivate osteoclasts and osteoblasts by inhibiting proliferation, differentiation and mineralisation. ${ }^{6,7}$

The commonly used drugs for osteoporosis are bisphosphonates. These drugs have a strong affinity for calcium of hydroxyapatite and also affect osteoclast enzyme farnesyl-diphosphate synthase in the HMG-CoA reductase pathway. ${ }^{8}$ They also inhibit osteoblast proliferation, differentiation and function, which, in turn leads to osteonecrosis. ${ }^{9}$ In such cases there is a need for stimulation of bone remodelling and angiogenesis.

The two major factors that have a stimulatory effect on the cellular growth process are oxygen supply and temperature. It has been shown that elevated temperature above the physiological normal range has a stimulatory effect on bone growth, via stimulation of cell proliferation and differentiation and also affecting the bone microenvironment by stimulating growth factors. Several studies reported a positive effect by thermotherapy in the treatment of various clinical diseases like bone malignancies, inflammatory osteoarticular disorders and bone metastasis. ${ }^{10,11}$ But still the underlying mechanism by which temperature interacts with bone cells remains controversial. We carried this study to examine the effect of mild heat-shock on osteoblast proliferation and mineralization, following treatment with bisphosphonates.

\section{MATERIALS AND METHODS}

\section{Cell culture}

MC3T3 cells are new-born mouse calvarial-derived cells, which have been characterised for their osteoblast precursor-like properties. All cell culture procedures were performed in a sterile air-flow chamber. Cells were cultured in alpha minimum essential medium supplemented with 10\% Foetal Calf Serum (FCS), 2 mmol L-glutamine and 100U/ml each of penicillin/streptomycin and were incubated at $37^{\circ} \mathrm{C}$ in humidified $5 \%$ $\mathrm{CO}_{2}$.

\section{Mild heat-shock treatment}

MC3T3 cells were seeded in $25 \mathrm{~cm}^{2}$ flasks and incubated for $24 \mathrm{hr}$ at $37^{\circ} \mathrm{C}$, in $5 \% \mathrm{CO}_{2}$ and $95 \%$ air. Heat shock was administrated by placing the flasks in a temperature-regulated water bath. The temperature was maintained within the error limits of $\pm 0.1^{\circ} \mathrm{C}$. The flasks were immersed in the water bath at various predetermined temperatures of $32^{\circ} \mathrm{C}, 42^{\circ} \mathrm{C}$

This is an open access article distributed under the terms of the Creative Commons Attribution-NonCommercial-ShareAlike 4.0 License, which allows others to remix, tweak, and build upon the work non-commercially, as long as the author is credited and the new creations are licensed under the identical terms. 
and $47^{\circ} \mathrm{C}$ for 2 and $5 \mathrm{~min}$. One group of cells was left untreated in the incubator at $37^{\circ} \mathrm{C}$. All the flasks were incubated at $37^{\circ} \mathrm{C}$ for a further $24 \mathrm{hr}$ to allow for the expression of heat-shock proteins.

\section{Bisphosphonate drugs}

The selected BP drugs have an established route of administration and mechanism of action. Pamidronate was administered intravenously, whereas alendronate was orally administered. The concentration range of the tested bisphosphonates was based on the information provided in the literature and on preliminary experiments, which allowed us to exclude the cytotoxic dose.

\section{Proliferation}

Proliferation was measured using the methylene blue staining technique. At the end of the experimental period, the cells were washed and fixed with methanol for $2 \mathrm{~min}$, after which $0.1 \%$ methylene blue in $0.01 \mathrm{M}$ borate buffer, $\mathrm{pH} 8.5$, was added to each well and left for $30 \mathrm{~min}$. The excess dye was removed by thoroughly washing with borate buffer then leaving to dry. The dye from the stained cells was eluted using $100 \mu \mathrm{l}$ of $0.1 \mathrm{~N} \mathrm{HCl}$ with $2 \%$ ethanol. The absorbance of each well was measured on an automated spectrophotometer at $650 \mathrm{~nm}$.

\section{Bone nodule formation}

For the mineralised nodule formation assay, the mineralised matrices were analysed using alizarin red staining. In brief, the cell cultures were twice washed with Phosphate Buffered Saline (PBS) and fixed with 2.5\% glutaraldehyde for $3 \mathrm{~min}$. Next, the cells were washed three times with $70 \%$ ethanol, left to dry for $30 \mathrm{~min}$, treated with a $2 \%$ alizarin red $\mathrm{S}$ solution for $20 \mathrm{~min}$ and washed three times to remove the remaining staining. The stains were then eluted with $500 \mu \mathrm{l}$ of $10 \%$ cetylpyridinium and transferred to a 96 -well micro plate in $100 \mu$ lamounts. The plate was then read by automated spectrophotometer at OD405 values.

\section{Alkaline phosphates activity}

The cells were seeded in a 24-well tissue culture plate at a density of 10x104 cells per well. By end of the experiment, 0.5\% Triton in PBS lysis buffer was added to each well, following removal of the old medium and washing with PBS. The cells were then transferred to micro tubes and stored at $-20^{\circ} \mathrm{C}$. An Alkaline Phosphatase Assay Kit (Bio Vision ${ }^{\circ}$ ) was used according to the manufacturer's instructions. The reaction mixtures were transferred to a 96-well micro plate and absorbance was read at $405 \mathrm{~nm}$ using a spectrophotometer.

\section{Statistical analysis}

Statistical analysis was carried out using the student $t$-test in GraphPad Prism software (v5.04), with $p<0.05$ considered to be statistically significant.

\section{RESULTS}

The effect of mild heat stress on osteoblast proliferation Osteoblast progenitors were exposed to temperatures of $32^{\circ} \mathrm{C}, 37^{\circ} \mathrm{C}$, $42^{\circ} \mathrm{C}$ and $47^{\circ} \mathrm{C}$ for 2 and $5 \mathrm{~min}$ for each and incubated for 24 or $72 \mathrm{hr}$. The results showed a significant inhibition of osteoblast growth and proliferation at both 24 and $72 \mathrm{hr}$ when exposed to a temperature of $32^{\circ} \mathrm{C}$ for 2 or $5 \mathrm{~min}$. In contrast, the osteoblasts that had been exposed to a temperature of $42^{\circ} \mathrm{C}$ for 2 min showed a significant increase in proliferation, as reflected by an increase in cell mass at $24 \mathrm{hr}(P<0.003)$. This effect of stimulation was not seen at $72 \mathrm{hr}$. Significant inhibition $(P<0.005)$ was seen at exposure to temperatures of both $42^{\circ} \mathrm{C}$ and $47^{\circ} \mathrm{C}$ for $5 \mathrm{~min}$ (Figure 1). When heat stress for $2 \mathrm{~min}$ and incubation for 3 days was tested, a significant inhibition of osteoblast proliferation $(P<0.01)$ was seen in all groups of osteoblasts exposed to temperatures of $32^{\circ} \mathrm{C}$ and $47^{\circ} \mathrm{C}$. Significant inhibition was seen in all the groups of osteoblasts exposed to $47^{\circ} \mathrm{C}(P<0.05)$ (Figure 2$)$.

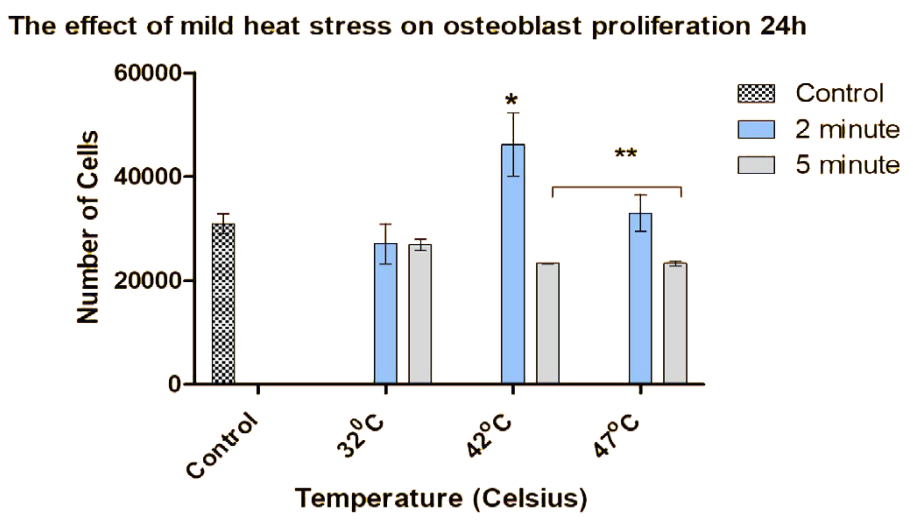

Figure 1: The effect of mild heat-stress for $2 \mathrm{~min}$ following $24 \mathrm{hr}$ of incubation. Significant stimulation of osteoblasts proliferation can be seen in the osteoblasts treated at $42^{\circ} \mathrm{C}$ for $2 \min \left({ }^{\star} P<0.003\right)$. Significant inhibition $\left.{ }^{* *} \mathrm{P}<0.005\right)$ can be seen at exposure to temperatures of both $42^{\circ} \mathrm{C}$ and $47^{\circ} \mathrm{C}$ for $5 \mathrm{~min}$.

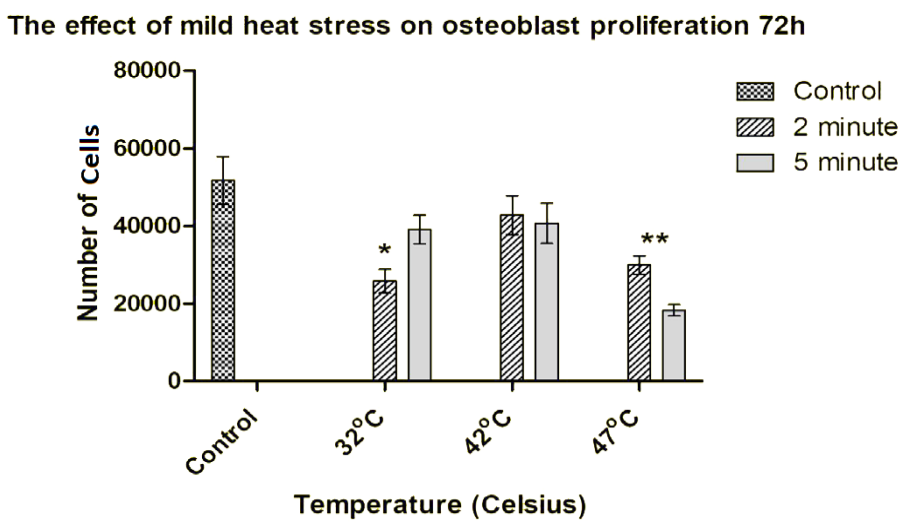

Figure 2: The effect of heat stress for $2 \mathrm{~min}$ and incubation for 3 days. Significant inhibition of osteoblast proliferation $\left({ }^{*} P<0.01\right)$ can be seen in all groups of osteoblasts exposure to temperatures of $32^{\circ} \mathrm{C}$ and $47^{\circ} \mathrm{C}$.

Significant inhibition can be seen in all the groups of osteoblasts exposed to $47^{\circ} \mathrm{C}\left({ }^{*} P<0.05\right)$.

\section{The effect of mild heat stress on osteoblast mineralisation}

The effect of heat stress on mineralised nodule formation over a 7-day incubation period was examined using Alizarin red-S staining. When the cells were exposed to a temperature of $32^{\circ} \mathrm{C}$, nodule formation was slightly inhibited when compared to the corresponding controls. At a temperature of $42^{\circ} \mathrm{C}$, nodule formation was significantly stimulated when compared to controls for both 2 and 5 min exposures. There was a significant increase in nodule formation at $42^{\circ} \mathrm{C}$ in cells exposed for 2 and $5 \min (P<0.05)$ compared to the controls. Heat had no effect on cell mineralisation at a temperature of $47^{\circ} \mathrm{C}$ (Figure 3).

\section{The effect of mild heat-stress on alkaline phosphates activity}

Cells incubated for $2 \mathrm{~min}$ at $42^{\circ} \mathrm{C}$ and $47^{\circ} \mathrm{C}$ were stimulated to find out whether they synthesise more alkaline phosphatase compared to the control cultures. However, there was no difference from the control group when incubated for $5 \mathrm{~min}$ at $32^{\circ} \mathrm{C}, 42^{\circ} \mathrm{C}$ and $47^{\circ} \mathrm{C}$ (Figure 4 ). 


\section{Experiment to determine if heat stress can reverse the effect of bisphosphonates on MC3T3 mineralisation}

In order to investigate whether heat can reverse the action of bisphosphonates, two groups of osteoblasts were seeded in a 24-well plate at a density of 30,000 cells per well and then left to attach overnight. The medium containing $15 \mu \mathrm{M}$ and $25 \mu \mathrm{M}$ of drug, was then changed and the cells were incubated for 7 days. At the end of day 7, the medium was changed and group 1 was treated with heat for 2 min at $42^{\circ} \mathrm{C}$, while the other group was treated with growth media. The results showed that heat reversed the inhibitory effect of the bisphosphonates compared to treatment with oestrogenic media. The results showed that heat stress significantly stimulated osteoblast progenitor mineralisation following drug treatment for 7 days compared to the group that was treated with oestrogenic media alone. $(P<0.04, P<0.009)$. These Alizarin red-S stain assays showed that a high temperature of $42^{\circ} \mathrm{C}$ for a short period induced the rate of mineralisation of the $\mathrm{MC} 3 \mathrm{~T} 3$ cell line following treatment with bisphosphonates (Figure 5).

\section{Experiment to determine if heat stress can reverse the effect of bisphosphonates on MC3T3 proliferation}

Osteoblast proliferation was investigated to observe whether heat stress of $42^{\circ} \mathrm{C}$ for $2 \mathrm{~min}$, following treatment with pamidronate and alendronate for 3 days, could reverse the action of both drugs. The cells were divided into two groups and both were treated with different concentrations of drugs. On Day 3, the medium was changed and group 1 was exposed to heat stress at $42^{\circ} \mathrm{C}$ for $2 \mathrm{~min}$. The other group of cells was incubated with growth media. The results showed that heat treatment stimulated cell proliferation following drug treatment for 7 days compared to treatment with growth media only. The results showed that heat stress treatment can stimulate osteoblast proliferation following treatment with these drugs for 7 days, compared to treatment with growth media only (Figure 6).

\section{DISCUSSION}

In the present study, we examined the effect of heat on osteoblast precursors following bisphosphonate treatment. Our results suggest that even an exposure of $47^{\circ} \mathrm{C}$ for $5 \mathrm{~min}$ caused cell death and so prevented cells from proliferating as the cell number was reduced. Previous similar suggested that $47^{\circ} \mathrm{C}$ is the threshold temperature at which bone-cell damage occurs. ${ }^{12}$ At the same time bone-cell necrosis and subsequent apoptosis without signs of angiogenesis recovery occurs when bone is

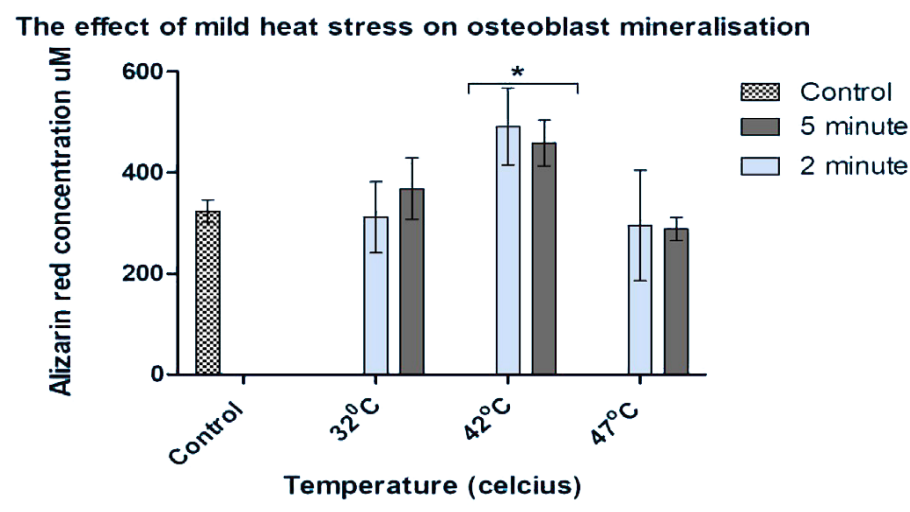

Figure 3: The effect of mild heat stress for 2 and 5 min after 10 days of incubation. There was a significant increase in nodule formation at $42^{\circ} \mathrm{C}$ in cells exposed for $2 \mathrm{~min}$ and $5 \mathrm{~min}\left({ }^{*} P<0.05\right)$ compared to the controls.
The effect of mild heat stress on ALP activity

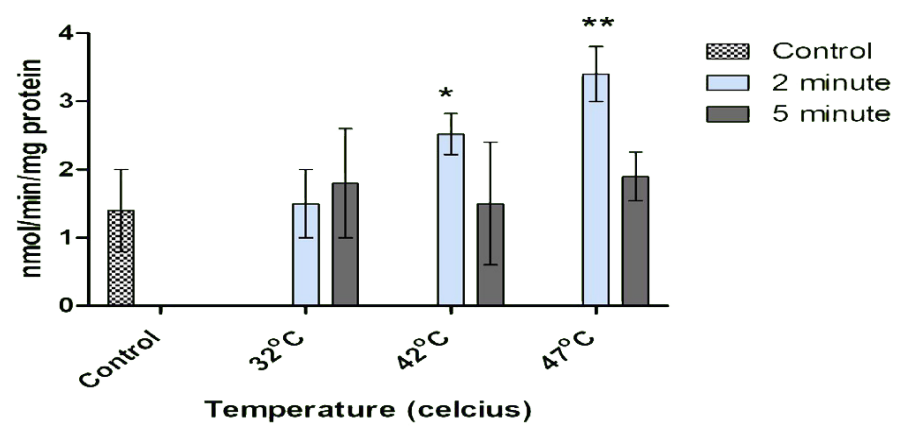

Figure 4: Cells incubated for $2 \mathrm{~min}$ at temperatures of $42^{\circ} \mathrm{C}$ and $47^{\circ} \mathrm{C}$ were stimulated to synthesise significantly more alkaline phosphatase compared to the control cultures $(p<0.01)$. There was no difference from the control group when incubated for $5 \mathrm{~min}$ at $32^{\circ} \mathrm{C}, 42^{\circ} \mathrm{C}$ and $47^{\circ} \mathrm{C}$

Heat treatment effect on Cells proliferation following Bisphosphonate

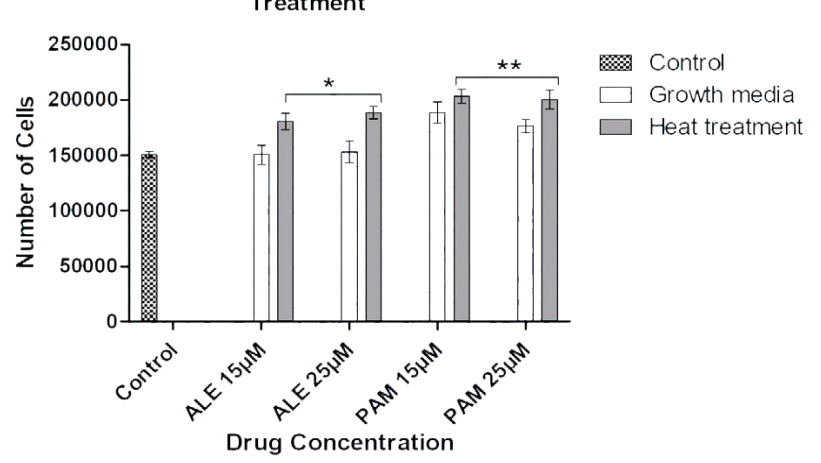

Figure 5: Cells were divided into two groups, which were treated with different concentrations of drugs. On Day 7, the medium was changed and group 1 was exposed to heat stress at $42^{\circ} \mathrm{C}$ for $2 \mathrm{~min}$. The second group was incubated in only osteogenic media. The results showed that heat stress significantly stimulated osteoblast progenitor mineralisation following drug treatment for 7 days compared to the group that was treated with osteogenic media alone. ( $\left.P<0.04,{ }^{* *} P<0.009\right)$

exposed to higher temperatures. This proves that the effect of heat on bone-cell growth and mineralisation depends on the degree of temperature. On contrary, reduced temperature induces osteoblast differentiation and mineralisation. ${ }^{13} \mathrm{We}$ found that $47^{\circ} \mathrm{C}$ as the threshold temperature, while $42^{\circ} \mathrm{C}$ for $5 \mathrm{~min}$ enhanced bone regeneration by stimulating osteoblast proliferation and mineralisation. Our findings indicate that application of heat treatment can be used as a new therapeutic tool in management of bone necrosis, such as BRONJ. We used MC3T3 cells, which are new-born mouse calvarial-derived cells characterised for their osteoblast precursor-like properties. Both have shown similar properties to osteoblast precursors and osteoblasts, but the main limitation of these cells is that they grow only as a two-dimensional monolayer in tissue culture flasks. In human bone, they grow in a three-dimensional environment, with the help of bone collagen and the mineral matrix. To sum up the first part of our study, osteoblast proliferation and differentiation are positively sensitive to temperature elevation, if a particular temperature and time are not exceeded.

High doses of pamidronate and alendronate $(100 \mu \mathrm{M})$ have shown significant inhibition of osteoblast proliferation and differentiation and will thus interfere with the bone remodelling process. Alendronate is an oral bisphosphonate with a primary indication for osteoporosis and the recommended dose is $10 \mathrm{mg} /$ day. Pamidronate was the first intravenous 
Heat treatment effect on Cells proliferation following Bisphosphonate Treatment

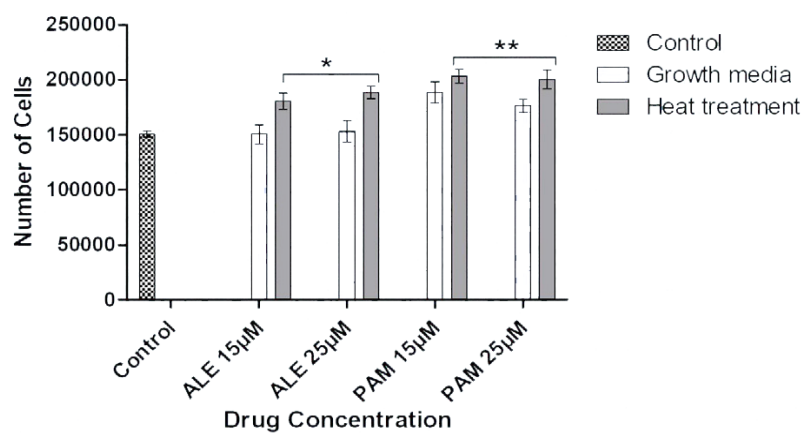

Figure 6: The cells were divided into two groups and both were treated with different concentrations of drugs. On Day 3, the medium was changed and group 1 was exposed to heat stress at $42^{\circ} \mathrm{C}$ for $2 \mathrm{~min}$. The other group of cells was incubated with growth media. The results showed that heat treatment stimulated cell proliferation following drug treatment for 7 days compared to treatment with growth media only.

BP to be prescribed for bone metastasis and the recommended dose is $90 \mathrm{mg} / 3$ weeks. ${ }^{14}$ This is a possible reason why the inhibitory effect of these drugs contributes to the pathogenesis of BRONJ and our study supports this hypothesis. The concentration that we used in the present study covered the physiological range detected in the resorption site and in bone from patients with BRONJ. ${ }^{15}$ Furthermore, it has been reported that the main action of bisphosphonates is a toxic effect on osteoclasts and other bone cells, because they have a high affinity to attach to bone hydroxyapatite. ${ }^{16}$ In our study, pamidronate and alendronate limited bone mineralisation in two ways: a cytotoxic effect was associated with a high dose and a low dose decreased cell proliferation. The cytotoxic effect of the bisphosphonates can interfere with osteoblast cell metabolism and cause cytoplasmic shrinkage. It is possible that inhibition of osteoblast precursors can reduce the bone remodelling process, thus, the risk of BRONJ will increase. We have also observed that alendronate and pamidronate may stimulate bone-nodule formation at relatively low doses of $100 \mathrm{nM}$ and $10 \mathrm{nM}$. The explanation for this finding is that it possible that the drug acts on different cellular mechanisms of bone cells. We observed that mild heat treatment can reverse the action of bisphosphonates and accelerate osteoblast healing following bisphosphonate treatment.

\section{CONCLUSION}

Temperature facilitates the stimulation of ontogenesis by osteoclasts, so this offers the potential to provide a non-invasive thermotherapy for bone necrosis, for example, BRONJ, or to treat bone defects following bone surgery by providing tissue regeneration. Mild heat-stress or treatment can reverse the action of bisphosphonate in two ways, either by enhancing osteoblast proliferation and differentiation, or by reducing the cytotoxic effect of bisphosphonates. This is could be of considerable therapeutic potential and a promising treatment for BRONJ.

\section{ACKNOWLEDGEMENT}

This study was supported by Prince Sattam bin Abdul-Aziz University, Ministry of Education, Saudi Arabia.

\section{CONFLICT OF INTEREST}

The authors declare no conflict of interest.

\section{ABBREVIATIONS}

ONJ: Osteonecrosis of the jaw; BRONJ: Bisphosphonate induced osteonecrosis of the jaws; FCS: Foetal Calf Serum.

\section{REFERENCES}

1. Buck DW, Dumanian GA. Bone biology and physiology: Part II. Clinical Correlates. Plast Reconstr Surg. 2012;129(6):950e-6e.

2. Buck DW, Dumanian GA. Bone biology and physiology: Part I. The Fundamentals: Plast Reconstr Surg. 2012;129(6):1314-20.

3. Seeman E. Bone modeling and remodeling. Crit Rev Eukaryot Gene Expr. 2009;19(3):219-33.

4. Chrcanovic BR, Reher P, Sousa AA, Harris M. Osteoradionecrosis of the jaws--a current overview--part 1: Physiopathology and risk and predisposing factors. Oral Maxillofac Surg. 2010;14(1):3-16.

5. Madrid C, Abarca M, Bouferrache K. Osteoradionecrosis: An update. Oral Oncol. 2010;46(6):471-4

6. Colella G, Campisi G, Fusco V. American Association of Oral and Maxillofacial Surgeons position paper: Bisphosphonate-Related Osteonecrosis of the Jaws-2009 update: the need to refine the BRONJ definition. J Oral Maxillofac Surg. 2009;67(12):2698-9.

7. Patntirapong S, Singhatanadgit W, Chanruangvanit C, Lavanrattanakul K, Satravaha Y. Zoledronic acid suppresses mineralization through direct cytotoxicity and osteoblast differentiation inhibition. J Oral Pathol Med. 2012;41(9):713-20.

8. Beek ERV, Cohen LH, Leroy IM, Ebetino FH, Lowik CW, Papapoulos SE. Differentiating the mechanisms of antiresorptive action of nitrogen containing bisphosphonates. Bone. 2003;33(5):805-11.

9. Compston J. Pathophysiology of atypical femoral fractures and osteonecrosis of the jaw. Osteoporos Int. 2011;22(12):2951-61.

10. Takeda T, Etani M, Kobayashi S, Takeda H. The effect of immunotherapy and hyperthermia on patients with advanced or recurrent breast cancer. Gan To Kagaku Ryoho. 2013;40(12):1596-9.

11. Gao Y, Gou T, Feng L, Wang F. Update of research on hyperthermia in relief of bone metastasis pain. Zhongguo Gu Shang. 2013;26(4):354-6.

12. Eriksson AR, Albrektsson T. Temperature threshold levels for heat-induced bone tissue injury: A vital-microscopic study in the rabbit. J Prosthet Dent. 1983;50(1):101-7.

13. Shui $C$, Scutt A. Mild heat shock induces proliferation, alkaline phosphatase activity and mineralization in human bone marrow stromal cells and Mg-63 cells in vitro. J Bone Miner Res. 2001;16(4):731-41.

14. Lowry J. Oral and Intravenous Bisphosphonate-Induced Osteonecrosis of the Jaws: History, Etiology, Prevention and Treatment. Ann R Coll Surg Engl. 2009;91(5):446

15. Sato M, GrasserW, Endo N, Akins R, Simmons H, Thompson DD, et al. Bisphosphonate action: alendronate localization in rat bone and effects on osteoclast ultrastructure. J Clin Invest. 1991;88(6):2095-105.

16. Hughes DE, Wright KR, Uy HL, Sasaki A, Yoneda T, Roodman GD, et al. Bisphosphonates promote apoptosis in murine osteoclasts in vitro and in vivo. J Bone Miner Res. 1995;10(10):1478-87.

Article History: Submission Date : 21-05-2019; Revised Date : 23-07-2019; Acceptance Date : 01-10-2019.

Cite this article: Alqhtani N, Alenazy A, Nasyam FA, Mehaji S. Influencing Effect of Heat Therapy on Osteoblasts Growth and Differentiation following Treatment with Bone Antiresorptive Drugs. J Young Pharm. 2018;10(4):395-8. 